\title{
Trajetórias de vida e formação de educadores sociais nos Centros Pop da Região Metropolitana de Vitória/ES
}

\author{
Samuel Coelho da Silva a \\ Rosianny Campos Berto ${ }^{b}$ \\ Liana Abrão Romera c
}

\section{Resumo}

Este artigo investiga trajetórias de vida e formação de educadores sociais que atuam no Centro de Referência Especializado para a População em Situação de Rua (Centro Pop) do Estado do Espírito Santo. Objetiva produzir reflexões sobre suas experiências formativas na relação com as proposições de Paulo Freire sobre a Educação Social e com as prescrições para sua formação no contexto atual. Analisa narrativas de trajetórias pessoais e formativas de seis educadores sociais que atuam em três unidades do Centro Pop situadas em diferentes municípios da Região Metropolitana de Vitória/ES. Considera que a atuação dos educadores sociais se baseia mais nas experiências de vida e de formação restrita do que na relação com uma preparação específica, politicamente engajada, que subsidie um trabalho qualitativo com pessoas em situação de rua atendidas nas unidades do Centro Pop.

Palavras-chave: Educador Social. Centro Pop. Trajetória de Formação.

\section{Introdução}

Este estudo investiga trajetórias de vida e formação de educadores sociais que atuam em três unidades do Centro de Referência Especializado para a População em Situação de Rua (Centro Pop) do Estado do Espírito Santo; produz reflexões sobre as narrativas desses sujeitos na relação com propostas que, historicamente, orientaram um olhar para sua atuação numa perspectiva pedagógica, de matriz freireana, acerca do educador social de rua; ao mesmo tempo, avalia o modo

\footnotetext{
a Prefeitura Municipal de Serra, Serra, ES, Brasil.

b Universidade Federal do Espírito Santo, Vitória, ES, Brasil.

Universidade Federal do Espírito Santo, Vitória, ES, Brasil.

Recebido em: 01 out. 2018.

Aceito em: 03 dez. 2019.
} 
como esses profissionais têm sido contemplados pelas políticas públicas, no que envolve sua preparação para trabalho tão complexo, bem como sua valorização como profissional.

A obra de Paulo Freire, conhecida internacionalmente, propôs um olhar para o educador como sujeito que, ao mediar o processo de aquisição do conhecimento, em diferentes instâncias educativas, atua como meio para a transformação social daqueles que vivem em contextos menos favoráveis e desiguais. É com base nessa orientação que buscamos compreender o modo como educadores sociais dos Centros Pop de Vila Velha, Serra e Vitória, municípios da região metropolitana de Vitória/ES ${ }^{1}$, se veem em seus processos formativos para a atuação com a população em situação de rua.

Pautados em Josso (2004), tomamos como fontes narrativas de trajetórias pessoais e autoformativas de seis educadores sociais que atuam nesses espaços de acolhimento, em busca de compreender o modo como as experiências construídas ao longo da vida interferem no trabalho que realizam. As narrativas foram tomadas durante oito meses de incursão nas três unidades do Centro de Referência Especializado para a População em Situação de Rua analisadas neste estudo.

Os Centros Pop são espaços de acolhimento previstos pela Lei Orgânica de Assistência Social (Loas), (BRASIL,1993)². Trata-se de serviço especializado que oferece atendimentos individuais e coletivos a pessoas em situação de rua, por meio de oficinas e atividades de convívio e socialização, com foco em ações que incentivem o protagonismo e a participação social dos sujeitos. Busca, assim, contribuir para a construção de novos projetos de vida, dentro das escolhas individuais; para resgate e preservação da integridade e da autonomia; e, para a reintegração à família e à comunidade (BRASIL, 2017).

Com base na Política Nacional para a População em Situação de Rua, instituída pelo Decreto $\mathrm{n}^{\circ} \mathbf{7 . 0 5 3}$, de 23 de dezembro de 2009, a referida população é definida como:

[...] grupo populacional heterogêneo que possui em comum a pobreza extrema, os vínculos familiares interrompidos ou fragilizados e

\footnotetext{
A Região Metropolitana de Vitória, criada em 1995 pela Lei Complementar Estadual n 58/95 (ESPÍRITO SANTO, 1995), é composta por sete municípios: Cariacica, Fundão, Guarapari, Serra, Viana, Vila Velha e a Capital Vitória. Disponível em: http://www.al.es.gov.br/antigo_portal_ales/images/leis/html/LC\%2058.html. Acesso em: 20 jan. 2018.

2 Promulgada para regulamentar os artigos 203 e 204 da Constituição, pela Política Nacional de Assistência Social (Pnas), de 2004.
} 
a inexistência de moradia convencional regular, e que utiliza os logradouros públicos e as áreas degradadas como espaço de moradia e de sustento, de forma temporária ou permanente, bem como as unidades de acolhimento para pernoite temporário ou como moradia provisória (BRASIL, 2009a).

Como profissionais de nível médio e, em alguns casos, de nível superior, os educadores sociais compõem uma equipe multidisciplinar ${ }^{3}$ que exerce papel importante no processo de acompanhamento dos sujeitos que frequentam esses centros. A esses profissionais, que passam a maior parte do tempo com os acolhidos, cabe a organização do espaço, a mediação das relações, a abordagem social e o desenvolvimento de oficinas socioeducativas. Exercem, assim, um papel que, em sua origem, é pedagógico.

Esse é um trabalho que requer sensibilidade para captar as necessidades dos atendidos. Por vezes, essas habilidades são desenvolvidas em processos de preparação mais formalizados, mas podemos sinalizar que, nos casos específicos dos Centros Pop, onde atuam os sujeitos dessa investigação, essas habilidades são construídas no cotidiano do trabalho e nas experiências anteriores. É no fazer diário que esses educadores aprendem a lidar com as questões complexas que envolvem uso e abuso de substâncias psicoativas, ausência de moradia fixa, conflitos relacionais, problemas de saúde, desemprego, perda de vínculos familiares, entre outros.

No entendimento de Freire (1989), o educador social tem importância central na transformação dessa realidade. Ao colocar-se como "[...] pessoa, como agente, respeitando a individualidade [do outro], seus valores e suas expectativas" (FREIRE, 1989, p. 13), o educador social representa o sujeito da escuta atenta, capaz de agir politicamente diante das desigualdades sociais vivenciadas. Caberia a ele buscar, junto aos assistidos, caminhos de superação da sua realidade. $\mathrm{Na}$ perspectiva freireana, esse profissional é alguém que deve trabalhar pelo oprimido e não pelo opressor, que deve identificar-se com as classes populares, que precisa ter "paciência histórica" para abordar o sujeito que necessita de acolhimento e encorajamento. Deve ser, também, alguém preparado, teóricopedagogicamente, para uma intervenção que leve em conta os Direitos Humanos

\footnotetext{
Composta por profissionais de diversas áreas de atuação. Considerando-se o número de 80 indivíduos/ famílias, a norma sugere que a equipe seja constituída por: um(a) coordenador(a) com a formação em Serviço Social ou Psicologia; dois assistentes sociais e dois psicólogos/as, para desenvolverem o acompanhamento dos assistidos; um técnico de nível superior que, preferencialmente, tenha formação em Antropologia, Arteeducação, Direito, Pedagogia, Sociologia ou Terapia Ocupacional, e quatro profissionais de nível superior ou médio, que, na região investigada, denominam-se educadores sociais - para realização do serviço especializado de abordagem social - e dois auxiliares administrativos de nível médio.
} 
e que seja comprometido "[...] com a promoção da justiça social e com o respeito à dignidade humana” (CARVALHO; ESTEVÃO, 2013, p. 414).

\section{O educador social e o processo de acolhimento às pessoas em situação de rua}

O educador social é um elemento significativo do movimento pela Educação Popular que tem ganhado espaço nas discussões acadêmicas e no meio social desde a década de 1990. A história da Educação Social no Brasil remonta, segundo Oliveira (2007), às lutas ensejadas na década de 1970 por grupos de intelectuais, trabalhadores sociais e religiosos, preocupados com a situação de crianças e adolescentes que habitavam as ruas brasileiras, após o acentuado êxodo rural-urbano, que incidiu, entre outras consequências, em um crescimento desordenado das periferias das grandes cidades (FREIRE, 1989). Nesse período, o governo militar havia promovido uma política econômica que submetia o Brasil ao capital internacional e tinha como consequência o enriquecimento dos mais ricos, por meio da concentração de renda, e o empobrecimento dos mais pobres, com o consequente aumento do desemprego e aproximação, cada vez maior, da miséria e das ruas ${ }^{4}$.

Visando a "limpar" as vias públicas, o governo militar criou, dentro do Plano Nacional do Bem-Estar do Menor (PNBEM), as Fundações Estaduais do BemEstar do Menor (Febem), que deveriam promover abordagens socioeducativas, mas que terminaram como instrumentos de encarceramento e exclusão. Segundo Oliveira (2007, p. 140),

Afirmava-se um sistema de classes, e a intenção de se retirar do espaço público as classes inferiores, retornando-os à invisibilidade - às prisões, aos manicômios e às instituições correcionais.

\footnotetext{
De acordo com Oliveira (2007), em busca de livrar o país da "ameaça comunista", o golpe de 1964 tinha como uma de suas finalidades fortalecer a ideologia de mercado no Brasil. Para isso, passou a promover uma política econômica submissa ao capitalismo internacional. Destacou-se, inicialmente, grande crescimento econômico - o chamado "milagre brasileiro" - que durou até meados dos anos 1970. Nesse período, o Brasil contraiu uma série de empréstimos de órgãos internacionais. Esse processo resultou numa crescente concentração de renda nas mãos dos mais ricos, aumentando as desigualdades e aprofundando dos problemas sociais, o que se agravou nos governos subsequentes. Fundamentado em dados produzidos pelo Ministério da Saúde e pelo Fundo das Nações Unidas para a Infância (Unicef), Oliveira (2007, p. 137-138) informa que, nesse período, "Cerca de $50 \%$ da população retinham $13,6 \%$ da riqueza nacional, e 13,13\% dela encontravam-se com 1\% dos brasileiros mais ricos. A diferença entre a média salarial dos mais pobres do Nordeste e Sudeste do país ficava em torno de 97\%. Estimava-se que cerca de 25 milhões de crianças e adolescentes até 18 anos viviam em famílias que ganhavam menos de meio salário mínimo per capita [...]. O índice de mortalidade infantil era de 60/1.000, mas nas classes mais abastadas caía para 10/1.000, enquanto nos estados mais pobres do Nordeste, a proporção alcançava 200/1.000; $21 \%$ da população brasileira eram consideradas analfabetas, e 47,3\% das casas não tinham saneamento básico e esgoto [...]. Entre 1983 e 1986 dobrou o número de trabalhadores com menos de 14 anos. [...] Em 1989, cerca de 30,4\% dos brasileiros até 17 anos trabalhavam".
} 
Estabelecia-se um pacto ideológico favorecendo o cumprimento da profecia que coloca os filhos dos pobres como futuros marginais, desatinados e sociopatas.

Esse modo de olhar para os pobres e os acontecimentos decorrentes das políticas sociais em colapso alimentaram o contexto de resistência, influenciando o surgimento da Educação Social de Rua. Com apoio da Pastoral do Menor, da Igreja Católica, e partindo de referenciais das pedagogias libertárias, um grupo de jovens com formação em Antropologia, Sociologia e Teologia, empenhados em promover a solidariedade humana, deu início a atividades com menores na Praça da Sé, em São Paulo. Denominavam-se Educadores Sociais de Rua. Suas referências tinham base na Teologia da Libertação, nas propostas de Paulo Freire, Emilia Ferreiro, Célestin Freinet, Anton Makarenko, Michel Foucault e Erving Goffman. Os primeiros Educadores Sociais de Rua eram autodidatas: "[...] não havia treinamento específico nem supervisão. No processo construtivista de um saber compartilhado, adotaram, como rotina, encontros semanais, em que trocavam ideias, avaliavam seu trabalho e balizavam suas experiências" (OLIVEIRA, 2007, p. 143).

\section{Aproximações com os Centros Pop no Espírito Santo}

Natalino (2016) produziu, a partir de dados fornecidos pelo Censo Suas (BRASIL, $2016)^{5}$, uma estimativa do número de pessoas que vivem em situação de rua no país. Apresentado em outubro de 2016, esse documento estimava haver 101.854 pessoas habitando as ruas, das quais cerca de $40 \%$ em municípios com mais de 900 mil habitantes, e cerca de $77 \%$, em municípios com mais de $100 \mathrm{mil}$ habitantes, considerados de grande porte. O mesmo censo indicou que o Brasil possuía, naquele ano, 230 Centros Pop, que atendiam menos de um quarto de toda essa população $0^{6}$.

De início, esses dados indicam que, mesmo que as políticas sociais tenham avançado em termos de proposição de cuidados, em alguns estados e regiões elas não são implementadas conforme estabelece a legislação. A ausência de dados sobre essa população, e a quantidade de Centros Pop distribuídos pelo Brasil indicam a invisibilidade dessa população para as políticas públicas.

\footnotetext{
O Censo Suas (Serviço Único de Assistência Social) é realizado pela Coordenação-Geral de Planejamento e Vigilância Socioassistencial, vinculado ao Ministério de Desenvolvimento Social e Combate à Fome (MDS); coleta dados das unidades dos Centros Pop de todo o país desde 2011.

6 Ao consultar os dados fornecidos pelo MDS, identificamos que a Região Norte (11 unidades) ao lado da Região Centro-Oeste (13 unidades) são as que possuem a menor quantidade de Centros Pop.
} 
O Espírito Santo, com 78 municípios e cerca de 4 milhões de habitantes 7 , conta com apenas quatro Centros Pop para atender a população em situação de rua. Três unidades estão localizadas na Região Metropolitana de Vitória e, outra, em Colatina, na região Centro-Oeste do estado do Espírito Santo. Todas foram implementadas a partir do ano de 2010, após a consolidação de políticas socioassistenciais no país.

O Instituto Jones dos Santos Neves (IJSN) apresentou, em 2018, relatório estimando que na Região Metropolitana de Vitória existiam aproximadamente 1.548 pessoas habitando as ruas. A pesquisa aponta que a maioria desses sujeitos concentravamse na capital, Vitória, por ser o município com maiores oportunidades de acesso à renda, ao trabalho e às condições gerais de sobrevivência.

Conforme a Tipificação Nacional dos Serviços Socioassistenciais (BRASIL, 2009b), o serviço especializado em questão deve acolher famílias e indivíduos que utilizam as ruas como espaço de moradia e/ou sobrevivência. As formas de acesso ocorrem por meio de encaminhamentos feitos pelo serviço de abordagem social, e de outros serviços socioassistenciais ou órgãos do sistema de garantia de direitos, ou por demanda espontânea.

O documento prevê que o funcionamento dos Centros Pop ocorra em dias úteis, com possibilidade de funcionar em feriados, finais de semana e período noturno; no geral, porém, funcionam durante cinco dias por semana, oito horas por dia. Os três centros investigados possuem peculiaridades na oferta do serviço e cumprem os requisitos referentes à jornada semanal proposta pelas orientações.

Conhecer essa organização prevista na legislação e cotejá-la com a realidade dos Centros Pop, contribui para compreender os elementos da formação dos educadores sociais, foco deste estudo. Compreendemos que as visitas aos centros para colher as narrativas possibilitariam entender o funcionamento dos espaços de atuação, as condições de trabalho que afetam a formação, as relações estabelecidas e os sujeitos envolvidos nesse cotidiano de acolhimento.

Em termos organizacionais, os Centros Pop investigados possuem dinâmica similar de acolhimento, principalmente em relação à distribuição do tempo. A rotina exige organização dos profissionais, de modo que horário de entrada, distribuição do café da manhã, almoço, desenvolvimento de atividades, distribuição do café

Dados sobre a estimativa da população brasileira disponibilizados pelo Instituto Brasileiro de Geografia e Estatística (IBGE, 2017). 
da tarde e atendimento aos assistidos pelos profissionais do psicossocial ou da assessoria jurídica ocorram sem problemas.

Para organizar os recursos humanos dos Centros Pop da Grande Vitória, os municípios seguem a Resolução ${ }^{\circ}$ 17, de 20 de junho de 2011 (BRASIL, 2011a), que orienta a atuação dos profissionais nos serviços socioassistenciais, em consonância com a proposta da Norma Operacional Básica de Recursos Humanos do Sistema Único de Assistência Social (NOB/RH/Suas), que prevê a contratação de profissionais de diversas áreas.

Assim, as equipes são compostas por grupos também diversos de profissionais: coordenador, supervisor técnico, assistente social, psicólogo, assessor jurídico, nutricionista, cozinheiro, técnico administrativo, oficineiro, vigia patrimonial, auxiliar de serviços gerais, educador social de nível superior e educador social de nível médio. Somente a unidade de Vitória possui o cargo para educadores com Ensino Superior.

Com base no Regimento Interno do Centro de Referência Especializado para a População em Situação de Rua do município de Vitória, as atribuições do educador social de nível superior envolvem: acolhimento dos assistidos, escuta qualificada; planejamento, organização, orientação de atividades e supervisão dos oficineiros e dos educadores de nível médio; atuação nas reuniões de planejamento em equipe, treinamento e encontros de capacitação profissional internos e externos.

Ao educador social de nível médio cabe: recepção aos assistidos e organização da dinâmica cotidiana do espaço; orientação sobre os atendimentos psicossociais; entrega de kits de higiene pessoal, alimentos e doações de roupa; manutenção e controle de entrada e saída dos assistidos; elaboração de relatórios de suas atividades; respeito ao sigilo a fim de proteger as informações sobre os assistidos; participação em reuniões técnicas e/ou administrativas, de treinamento e encontros de capacitação profissional internos e externos, dentre outras funções.

Assim, os primeiros contatos com as unidades socioassistenciais para o desenvolvimento da pesquisa foram realizados no ano de 2017. Considerando a viabilidade geográfica e a maior concentração populacional, optamos por realizar a investigação nas unidades da Região Metropolitana de Vitória. O Centro de Referência Especializado para a População em Situação de Rua de Vila Velha foi a primeira unidade contatada, seguida do Centro de Vitória e do de Serra.

No processo de aproximação com os educadores sociais de cada unidade, aplicamos 20 questionários, dos quais, 15 foram devolvidos. A partir dos dados 
de identificação e de inserção pessoal e social contidos nesse instrumento, foi possível determinar critérios de seleção para as entrevistas, considerando as trajetórias de formação que seriam analisadas. Entre eles, privilegiamos o tempo de atuação superior a 12 meses e a experiência em programas ou projetos sociais diversos. Consideramos esses elementos como fundamentais numa investigação que se pauta pelas trajetórias de vida e formação. Na ausência de um desses critérios, optamos, ainda, por manter ao menos um entrevistado de cada Centro de Referência Especializado para a População em Situação de Rua, de modo a garantir a representatividade das três unidades investigadas.

As entrevistas narrativas - fontes para compreender o processo de formação e (auto)formação presentes nas trajetórias (pessoais e profissionais) dos educadores sociais - guiadas por um roteiro prévio e aberto, foram gravadas, transcritas, categorizadas e analisadas, tomando como orientação a técnica de triangulação proposta por Triviños (1987) e, especial, a metodologia da pesquisa-formação (JOSSO, 2004, p. 25), baseada na "[...] preocupação com que os autores de narrativas consigam atingir uma produção de conhecimentos que tenham sentido para eles e que eles próprios se inscrevam num projeto de conhecimento que os institua como sujeitos".

\section{Os educadores sociais dos Centros Pop da Grande Vitória: trajetórias e formação}

Ao analisarmos as narrativas dos educadores sociais sobre suas trajetórias, identificamos três tipos de experiências que consideramos formativas: a) formação ampliada, caracterizada pelas experiências acumuladas na trajetória pessoal; b) formação restrita, construída nos bancos escolares: Educação Básica, Ensino Profissionalizante e Ensino Superior; e c) formação específica, que aborda a preparação mais direta para atuar em serviços socioassistenciais, além daquela que acontece no cotidiano do Centro de Referência Especializado para a População em Situação de Rua.

Quando trata das narrativas de formação, Josso (2004) ressalta que o processo de construção de uma narrativa é também um processo de realimentação das experiências que construímos ao longo da vida. Segundo a autora, aquele que narra compartilha, ao mesmo tempo em que é sujeito-aprendente. Ao rememorarem suas trajetórias de vida, os entrevistados abordaram aspectos que não podem ser ignorados - empregos e vínculos anteriores, vivências em instituições diversas -, mas também puderam, assim o cremos, construir uma imagem que lhes possibilitasse refletir sobre essas experiências. 
A começar por aquelas que consideramos como experiências de formação ampliada, Josso (2004) indica que elas se configuram por vivências particulares que só alcançam o nível de experiências quando são acompanhadas de reflexão sobre o que foi observado, percebido e sentido. A ideia é que o rememorar desses acontecimentos propicia algo novo em termos de aprendizado, capaz de provocar outros saberes-fazeres na atuação profissional.

O desafio foi identificar, nessas narrativas, elementos das trajetórias de vida e formação dos educadores sociais, que interferissem na atuação no Centro de Referência Especializado para a População em Situação de Rua, pois como lembra Vangrelino (2005, p. 8), os educadores sociais “[...] se formam como tais no espaço familiar, escolar, nas experiências da maternidade, da paternidade e nas experiências profissionais anteriores e exteriores ao projeto educacional/ assistencial no qual estão inseridos".

Entre os primeiros fragmentos de memórias narrados por esses sujeitos, oriundos de realidades diversas, destaca-se a religião, praticada por eles, de maioria católica. Os educadores MNS29 e FNM50 $0^{8}$ relataram a busca por conhecimento mais aprofundado nesse quesito, inclusive em termos de formação acadêmica, como destaca o educador MNS29, que realizou curso de Teologia. Para esse educador, a relação com a religião favoreceu o desenvolvimento de habilidades necessárias ao trabalho no Centro Pop, como capacidade de liderança e de trabalho em equipe. Assim, relatou:

[...] da experiência religiosa, a visão de equipe que eu trago se dava também em minha atuação na comunidade. Isso porque não tem essa coisa que o cara é bíblico, o cara é pastor, o cara é padre. Enfim, acho que todo mundo tem o mesmo peso de responsabilidade. Trabalhar junto com o mesmo objetivo e o que respingar para a sua área específica. Entretanto, é lógico que cada um vai trabalhar em sua área específica, mas o que eu puder fazer pra ajudar eu vou fazer; então contribui para o momento que chegou, porque eu não imaginava que ia atuar como educador social de nível superior aqui [...] (MNS29, 2017).

O diálogo, que, segundo indicam os relatos, tem relação com a vivência religiosa, assume papel estratégico no trabalho: "[...] aqui não adianta ir com força, que

\footnotetext{
8 Os educadores sociais entrevistados são identificados neste texto por uma sigla composta pelas letras $\mathrm{F}$ ou M (que indicam o sexo), seguidas das letras referentes ao nível de escolaridade: NS (Nível Superior) ou NM (Nível Médio), e da idade.
} 
você não consegue. Se um estiver brigando e você vai segurar, não é o ideal, tem que ser no diálogo, e também falar da palavra de Deus pra eles, ou seja, quebrar o clima" (FNM50, 2017).

Os educadores assumem a linha de frente na atuação com a população em situação de rua. A palavra "diálogo", encontrada nos fragmentos de falas, representa um recurso importante no desenvolvimento das tarefas no Centro de Referência Especializado para a População em Situação de Rua. Para Freire (1996), o diálogo, no sentido pedagógico, é fundamental para o processo de transformação social, e o educador precisa ser preparado dentro dessa perspectiva. No caso dos educadores cujos relatos são analisados, prevalecem tentativas de diálogo orientado pelas experiências de vida, muito mais do que por formação específica, que não é garantida pelo Estado.

Ao narrar seu processo formativo, o educador MNM48 relata suas vivências esportivas e seu contato com internos do orfanato em que estudou: "No orfanato eu tive convívio com os internos; tive um vínculo muito forte com os adolescentes de lá" (MNM48, 2017). Quando saiu da instituição, ainda adolescente, trabalhou em projetos sociais, com ênfase no esporte, para crianças e adolescentes em situação de rua. Essas experiências potencializaram sua atuação no Centro de Referência Especializado para a População em Situação de Rua. No entendimento desse educador, as experiências anteriores o credenciaram a pleitear a vaga e a assumir o cargo.

Na relação com a formação ampliada, aparece outro conjunto de experiências aqui denominada formação restrita, referente à trajetória escolar dos educadores sociais, indicando a aquisição de conhecimentos mais sistematizados, mas sem relação direta com a área social, com seu campo de atuação.

No geral, realizaram a Educação Básica na escola pública, e alguns cursaram Ensino Técnico Profissional (na rede privada, especialmente) como alternativa para facilitar a busca por emprego, o que, segundo Brazorotto (2017), ocorre com maior frequência nas camadas populares brasileiras, com vistas à mobilidade social via Educação. Esse modelo de formação tem sido, nas últimas décadas, um caminho para inserção da população mais pobre no mundo do trabalho, especialmente entre os homens, como é o caso de dois educadores que, após o Ensino Médio, buscaram formação técnica - o que, segundo um deles, interfere positivamente em sua atuação no Centro de Referência Especializado para a População em Situação de Rua: 
[...] me ajudou bastante, até mesmo no curso técnico, por incrível que pareça. Mesmo que seja um ramo totalmente diferente, que é o de Mecânica, eu trouxe muita coisa pra minha vida profissional, como a questão da organização, de manter tudo alinhado, pois se uma coisa se perder no caminho pode prejudicar todo o processo de trabalho. Na Mecânica a gente tem alguns métodos de trabalho, a manutenção preventiva, a corretiva. Essa forma metódica tem influência no trabalho educacional, da atenção redobrada (MNS29, 2017).

Mesmo sem relação direta com a atuação dos profissionais na área socioassistencial, essa formação faz diferença para os educadores. O educador MNS29 ressalta as influências de duas áreas distintas e afirma aproveitar os saberes adquiridos no curso técnico, sobretudo os aspectos organizacionais. Já os saberes do curso de Teologia, segundo ele, influem no trabalho com as pessoas, nas relações interpessoais.

Ao relatar as dificuldades enfrentadas pelos pares, a educadora FNS36 aponta possibilidades de aproveitamento das diversas áreas de formação (ou de experiências extras) dos educadores sociais que atuam na sua equipe, os quais, no seu entendimento, possuem potencialidades que são desperdiçadas:

[...] eles deveriam ter mais instrumentos, assim como eu também: mais instrumentos e infraestrutura física e material como: computadores, laboratório de informática e instrumentos musicais. Isso porque temos pessoas com formação em diversas áreas [...] temos educadores físicos, músicos, técnicos de informática, porém, não conseguem desenvolver um trabalho em sua área de formação (FNS36, 2017).

A educadora entende que experiências e conhecimentos específicos poderiam ser mais bem aproveitados se houvesse infraestrutura adequada para desenvolver melhor atendimento aos assistidos.

O educador MNM48 procura articular no seu trabalho, conhecimentos adquiridos como esportista e, depois, no curso de Educação Física. Ao mobilizar esses saberes, salienta o quanto essa área pode contribuir com o serviço ofertado pelo Centro de Referência Especializado para a População em Situação de Rua. Mesmo reconhecendo que a Educação Física não está oficialmente inserida no serviço, e que sua remuneração não seja compatível com a de um profissional de Ensino Superior, ele vê vantagens na oferta dessas atividades. 
Destacam-se, também, as experiências com o magistério na atuação no Centro de Referência Especializado para a População em Situação de Rua. O educador MNM48 e a educadora FNM50 cursaram o magistério integrado ao Ensino Médio, experienciando a docência em diferentes contextos: na convivência com internos de um orfanato, em projetos sociais, em um Centro Municipal de Educação Infantil (Cmei), de onde vem, segundo eles, habilidades para lidarem com pessoas em situação de rua.

Há uma mobilização dos saberes adquiridos ao longo das formações ampliada e restrita, evidenciadas a partir das diferentes áreas de atuação, anteriores, como em projetos sociais, escolas, cursos profissionalizantes e prática de esportes. Ao falarem desses saberes, os educadores evidenciam a palavra "aprender":

Não tinha muita experiência para trabalhar em abrigo e não sabia como era. Então, fui aprendendo muita coisa (FNM31, 2017, grifo nosso).

[...] eu gosto mesmo de estar aqui, gosto de sentar no pátio, de ficar no meio deles, gosto de conversar, de ouvir as histórias de vida deles, pois eles têm muito pra passar pra gente, pra gente aprender mesmo. Tem coisas que eu [...] nunca tinha escutado [...] (FNS36, 2017, grifo nosso).

Freire (1996, p. 12) orienta que o "[...] ensinar inexiste sem o aprender e vice-versa e foi aprendendo socialmente que, historicamente, mulheres e homens descobriram que era possível ensinar". Identificamos nas narrativas dos educadores sociais a importância dada ao processo de aprendizagem em suas trajetórias, seja fora do ambiente escolar, seja no desenvolvimento das funções na área socioassistencial.

Ressaltamos a relevância dessas experiências diversas, pois permitem a mobilização de múltiplos saberes para a atuação nos serviços socioassistenciais. Josso (2004) entende essas experiências como consciência sensível do indivíduo atento a si próprio, aos outros e ao seu ambiente. Elas permitem uma percepção do mundo em dimensões diversas.

A aprendizagem indicada nas falas sinaliza um processo constante nos Centros Pop da região metropolitana. Não diferente de outras profissões, os educadores sociais aprendem nas trocas de experiências. Na ausência de política de formação para esse serviço, conforme denuncia Vangrelino (2005), os educadores sociais mais experientes assumem a função de orientar os recém-chegados, estabelecendo-se aí um processo de formação baseado nos intercâmbios. 
A NOB/RH/Suas (BRASIL, 2006), assim como a Política Nacional (BRASIL, 2009a), preveem formação permanente dos educadores sociais, que amplie conhecimentos, habilidades, potencialidades e capacidades técnicas e gerenciais da equipe. Os elementos contidos nessa formação deveriam preparar os educadores para a implementação de um serviço de qualidade e com condições de aperfeiçoamento nas intervenções propostas, sendo capazes de superar aquilo que é apontado por Zucchetti e Moura (2010, p. 22) como “[...] um engajamento artificial, expresso [naquele] que, dificilmente, se vê como um 'instrumento de transformação social"”.

Numa orientação progressista e mais enraizada na perspectiva da Educação Social, essa formação deveria acontecer de forma contínua, possibilitando aos trabalhadores o conhecimento técnico, a capacidade política de compreender as mazelas, os processos de opressão e de criar meios para a busca da transformação social (FREIRE, 1987). Entretanto, como lembram Zuchetti e Moura (2010, p. 20), há tempos os projetos de caráter social deixaram de "[...] constituir-se em espaços estratégicos de lutas (e libertação) de setores populares".

Entre as indicações para formação permanente estão a participação em cursos, encontros, palestras, oficinas diversificadas e a realização de visitas técnicas a diferentes unidades e serviços socioassistenciais, mas as narrativas dos educadores sociais sobre a oferta dessa formação pela prefeitura indicam que:

[...] essa preparação é mínima. Ela acontece no dia a dia mesmo. [...] algumas coisinhas que a gente pega pra ler, um artigo ali outro aqui, mas sem aprofundar muito. É nas discussões do dia a dia, das reuniões, da experiência de outros aparelhos, de algumas palestras que a gente participa por ano; isso cerca de três ou quatro [...] (MNS29, 2017).

Ao considerarmos as orientações legais, não conseguimos identificar políticas regulares e sistematizadas de formação para os educadores sociais no âmbito dos municípios. O educador MNS29 diz que há iniciativas, porém, pontuais. O educador MNM48 relata, por exemplo, que a organização não governamental (ONG) responsável pela administração do serviço de Vitória promove acesso a alguns cursos de formação oferecidos pela prefeitura. Em sua avaliação, esses cursos contribuem para a atuação na área social e com práticas mais específicas, a exemplo da Educação Física - sua área de formação, a partir da qual elabora atividades que conduz no Centro de Referência Especializado para a População em Situação de Rua onde trabalha. 
Para fortalecer o processo de capacitação, sugerem-se ainda a formação de grupos de estudos, supervisão técnica ou assessoria externa de profissional com experiência e conhecimento em áreas estratégicas e reuniões sistemáticas de equipe. Essas iniciativas compreenderiam a formação em serviço, que não pode ser a única opção, “[...] uma vez que esses espaços são pouco reflexivos, tornando-se por vezes rotineiros além de assoberbados de tarefas" (ZUCCHETTI; MOURA, 2010, p. 24).

Entre os espaços para troca de experiência e formação em serviço estão as reuniões internas, de equipe, que têm frequência variada nos três cenários investigados - podendo ser semanais, quinzenais ou mensais, de acordo com a demanda do Centro de Referência Especializado para a População em Situação de Rua. Elas têm como objetivo tratar de assuntos administrativos, conhecimento da política, do fluxo, do cotidiano da unidade, de questões técnicas. Entendemos que esses espaços de discussão são importantes para manter a equipe coesa em suas ações, mas, também, para situar o educador social recém-contratado com relação a demandas, dificuldades e especificidades do serviço, ainda que não sejam suficientes para atender à complexidade do trabalho do educador social.

Souza Neto (2010) lembra que o campo de atuação do educador social é complexo e circundado

[...] por embates ideológicos, ações de grupos organizados, contendas políticas e religiosas, experiências de injustiça, perdas e frustrações. Tal contexto sociopolítico exige [do educador social] capacidade de se apropriar da realidade e nela intervir pedagogicamente, de mediar relações entre indivíduos, famílias e instituições, de modo a abrir perspectivas para o bem-estar individual e social (SOUZA NETO, 2010, p. 30).

$\mathrm{O}$ autor dialoga com a perspectiva freireana ao compreender, nos dias atuais, $\mathrm{o}$ trabalho do educador social como meio de combate às desigualdades, ideia que, em nosso entendimento, ganha força nos últimos anos, a partir do momento em que as condições conquistadas passam a ser ameaçadas, comprometendo a vida de pessoas em situação de vulnerabilidade. Neste sentido, as reuniões realizadas nos Centros Pop são um caminho, mas não atendem à necessidade de formação dos educadores sociais. É preciso que os gestores municipais viabilizem o previsto nos documentos acerca da Educação permanente de forma efetiva.

É importante que o processo permanente de capacitação seja planejado, contando com diversas possibilidades e momentos que 
envolvam: participação em cursos, encontros, oficinas e outros eventos e visitas técnicas a outras unidades e serviços para a troca de experiências; dentre outros (BRASIL, 2011b, p. 58).

As leis municipais relativas ao atendimento à população em situação de rua, que regem as unidades em questão neste estudo ${ }^{9}$, preveem garantias de acolhimento na rede socioassistencial, de dignidade e de acesso à cidade pelos assistidos, o que inclui formação adequada aos profissionais que trabalham com esse grupo.

Nos meses de visitas aos Centros Pop, observamos que os coordenadores estimulam a participação em eventos e cursos, mas não se viabilizam meios para liberação dos funcionários, com a manutenção do serviço em funcionamento. Os coordenadores compreendem a necessidade desse tipo de formação, mas esbarram nas demandas do cotidiano.

Dos três cenários analisados, a unidade de Vitória foi a que mais desenvolveu eventos formativos nos Centros Pop. Ainda que esses espaços sejam importantes para a formação dos educadores, direcionavam-se mais aos usuários do Centro de Referência Especializado para a População em Situação de Rua, ao tratarem de temas como doenças, direitos das mulheres e dos idosos.

No caminho da (auto)formação, os educadores sociais buscam uma preparação que os habilite a atuar nos Centros Pop, ora por meio das experiências oportunizadas pela formação ampliada, ora pela formação restrita, que, de alguma maneira, oportunizou o contato com a área social.

\section{Considerações finais}

A Educação Social, no modo como foi defendida por Paulo Freire e pelos grupos que deram início a esse modo de abordar, escutar e acolher o outro, propunha, na sua essência, que o educador social fosse o sujeito da sensibilidade, da capacidade de escuta, de diálogo e de intervenção pedagógica no sentido da transformação social daqueles que acolhe e que acompanha, no sentido de ouvir as histórias de vida e de contribuir para o resgate do humano, por vezes esquecido no indivíduo que, forçadamente, lança-se para a vida nas ruas. Essa essência política e engajada do educador social parece ter se perdido no tempo.

\footnotetext{
9 Especialmente a Lei n².678, de 3 de março de 2004, no município de Serra, e a Lei n 7.101, de 2 de outubro de 2007, no município de Vitória.
} 
Não se pode dizer que os educadores sociais dos nossos tempos, dos Centros Pop do Espírito Santo, não atuem pedagogicamente. Vimos por suas narrativas que, sim, suas ações são, em diversos momentos, pedagógicas e dialógicas. Mas, pelo alcance do trabalho desses indivíduos, a preparação que recebem (ou que não recebem, na maioria dos casos) termina por precarizar o seu trabalho, na medida em que precisam fundamentar suas ações em experiências anteriores, de vida, de formações outras, o que não é pouco.

Entendemos, portanto, que os saberes produzidos nos percursos individuais e coletivos dos educadores interferem profundamente em seu trabalho, no qual também se dispõem a ouvir outras histórias de vida e, à medida que ouvem e compreendem quem são aquelas pessoas, esvaziam-se, aos poucos, de uma visão estigmatizada para um olhar de respeito, de não julgamento. Sabemos que, sendo importantes, as experiências de vida não são suficientes para um trabalho que se queira pedagógico e politicamente engajado, com vistas à transformação social. A formação sistematizada e permanente precisa acontecer para que a atuação dos educadores sociais seja efetiva na redução das desigualdades sociais.

Para isso, entre os elementos que saltam das narrativas dos educadores como necessidade para sua formação, está a capacidade de dialogar, no sentido de falar e ser ouvido, escutar, mediar conflitos, influir na construção de projetos de vida de um grupo, por vezes desesperançado, que frequenta os Centros Pop da região da Grande Vitória.

A dimensão pedagógica que, historicamente, enraíza o papel do educador social foi mais bem percebida nos educadores com formação superior ou formação específica. Essas dimensões da formação fazem alguma diferença na atuação dos educadores sociais nos contextos investigados, principalmente, porque é mais comum que as ações desses sujeitos aproximem-se da perspectiva freireana, considerando que essa matriz é, de algum modo, conhecida por eles. Isso não significa que os educadores sociais de nível médio não realizem um trabalho pedagógico, mas que terminam por desenvolvê-lo em nível organizacional e menos como abordagem engajada, propositiva e transformadora. Além disso, ao considerarmos que os serviços socioassistenciais têm exigido, na contratação dos profissionais, experiência com a população em situação de rua ou na área social, amplia-se a procura dos educadores pela formação, para atenderem aos requisitos do cargo.

Importante salientar que os Centros de Referência Especializado para a População em Situação de Rua da Grande Vitória, mesmo enfrentando dificuldades, prestam 
serviço relevante para a região; os educadores sociais, principais referências para os sujeitos que acolhem, precisam ver-se como profissionais que carecem de atenção das políticas públicas, com investimento na qualificação, visando a conferir maior qualidade ao atendimento que prestam. Portanto, o investimento na formação dos trabalhadores de forma sistemática pode significar prioridade na oferta de ações direcionadas às necessidades das pessoas em situação de rua. 


\title{
Training and life trajectories of social educators in the Centros Pop of the Metropolitan Area of Vitória/ES
}

\begin{abstract}
This study investigates life trajectories and educational paths of social educators who work at the Special Reference Center for Homeless People (Centro Pop) in the State of Espirito Santo, Brazil. Based on the narratives of six social educators who work in three units of Centro Pop, that are located in different cities of the Metropolitan Area of Vitórial ES, it aims to reflect upon their formative experiences regarding Paulo Freire's thoughts on Social Education, as well as on the guidelines that inform their training in current contexts. It concludes that the performance of those social educators remains mostly based on life experiences and restricted training, rather than on a specific, politically engaged preparation that enables a quality work with homeless people attended in the units of Centro Pop.
\end{abstract}

Keywords: Social Educator. Centro Pop. Training Trajectory.

\section{Trajetorias de vida y formación de educadores sociales en los Centros Pop De La Región Metropolitana de Victoria/ES}

\section{Resumen}

Este artículo investiga las trayectorias de vida y la capacitación de educadores sociales que trabajan en el Centro de Referencia Especializado para la Población en Situación de Calle (Centro Pop) del Estado de Espirito Santo. Su objetivo es producir reflexiones sobre sus experiencias formativas en relación con las propuestas de Paulo Freire sobre Educación Social y con las prescripciones para su formación en el contexto actual. Analiza narrativas de trayectorias personales y formativas de seis educadores sociales que trabajan en tres unidades del Centro Pop ubicados en diferentes municipios de la Región Metropolitana de Vitória/ES. Considera que el trabajo de los educadores sociales se basa más en las experiencias de la vida y de capacitación restringida que en la relación con una preparación especifica y comprometida políticamente, que respalde un trabajo cualitativo con las personas en situación de calle atendidas en las unidades del Centro Pop.

Palabras clave: Educador Social. Centro Pop. Trayectoria de Formación. 


\section{Referências}

BRASIL. Decreto $n^{\circ} 7.053$, de 23 de dezembro de 2009a. Institui a Política Nacional para a População em Situação de Rua e seu Comitê Intersetorial de Acompanhamento e Monitoramento, e dá outras providências. Diário Oficial da União, Brasília, DF, 24 dez. 2009.

BRASIL. Lei no 8.742 , de 7 de dezembro de 1993. Dispõe sobre a organização da Assistência Social e dá outras providências. Diário Oficial da União, Brasília, DF, 8 dez. 1993.

BRASIL Ministério do Desenvolvimento Social e Combate à Fome. Secretaria Nacional de Assistência Social. Política Nacional de Assistência Social: PNAS/2004. Norma Operacional Básica: NOB/Suas. Brasília, DF, 2005. Disponível em: https://www.mds.gov.br/webarquivos/publicacao/assistencia social/Normativas/PNAS2004.pdf. Acesso em: 11 out. 2017.

BRASIL. Ministério do Desenvolvimento Social e Combate à Fome. Secretaria Nacional de Assistência Social. Política Nacional de Assistência Social. Norma operacional básica de recursos humanos do Suas:

NOB-RH/SUAS. Brasília, DF, 2006.

BRASIL. Ministério do Desenvolvimento Social e Combate à Fome. Conselho Nacional de Assistência Social. Resolução no 17, de 20 de junho de 2011a. Diário Oficial da União. Brasília, DF, 21 jun. 2011.

BRASIL. Ministério do Desenvolvimento Social e Combate à Fome. Conselho Nacional de Assistência Social. Resolução no 109, de 11 de novembro de 2009b. Aprova a Tipificação Nacional de Serviços Socioassistenciais, Diário Oficial da União, Brasília, DF, 25 nov. 2009.

BRASIL. Ministério do Desenvolvimento Social e Combate à Fome. Secretaria Nacional de Renda e Cidadania, Secretaria Nacional de Assistência Social. Orientações técnicas: Centro de Referência Especializado para a População em Situação de Rua (Centro Pop). Brasília, DF: Gráfica e Editora Brasil, 2011b. (Suas e população em situação de rua, v. 3). Disponível em: http://www.mds.gov.br/webarquivos/publicacao/assistencia_social/Cadernos/ orientacoes_centro_pop.pdf. Acesso em: 11 out. 2017.

BRASIL. Ministério do Desenvolvimento Social e Combate à Fome. Coordenação-Geral de Planejamento e Vigilância Socioassistencial. Censo Suas. Brasília, DF, 2016. Disponível em: http://aplicacoes.mds.gov.br/snas/ vigilancia/index2.php. Acesso em: 12 maio 2018. 
BRAZOROTTO, C. M. Quem são os estudantes do ensino médio profissionalizante no Brasil e na Alemanha? In: COLÓQUIO NACIONAL, 4.; COLÓQUIO INTERNACIONA, 1: A PRODUÇÃO DO CONHECIMENTO EM EDUCAÇÃO PROFISSIONAL, 2017, Natal, RN. Anais[...]. Natal: IFRN, 2017. Disponível em: https://ead.ifrn.edu.br/coloquio/anais/2017/. Acesso em: 16 jul. 2018.

CARVALHO, M. E. G.; ESTEVÃO, C. A. V. Pedagogia crítica e Direitos Humanos: fundamentos para uma proposta pedagógico-crítica em Direitos Humanos. Ensaio: Avaliação e Políticas Públicas em Educação, Rio de Janeiro, v. 21, n. 80, p. 405-432, jul./set. 2013. http://dx.doi.org/10.1590/S0104-40362013000300002

ESPÍRITO SANTO (ESTADO). Lei Complementar Estadual n ${ }^{\circ}$ 58, de 23 de fevereiro de 1995. Fica instituída a Região Metropolitana da Grande Vitória - RMGV, com vistas à organização, ao planejamento e à execução de funções públicas de interesse comum, no âmbito metropolitano. Vitória, 1995. Disponível em: http://www3.al.es.gov.br/Arquivo/Documents/legislacao/html/ LC\%2058.html. Acesso em: 15 out. 2018.

FREIRE, P. Educadores de rua: uma abordagem crítica: alternativas de atendimento aos meninos de rua. Bogotá: Unicef, 1989. (Série Metodológica, v. 1).

FREIRE, P. Pedagogia da autonomia: saberes necessários à prática educativa. São Paulo: Paz e Terra, 1996. (Coleção Leitura).

FREIRE, P. Pedagogia do oprimido. Rio de Janeiro: Paz e Terra, 1987.

INSTITUTO BRASILEIRO DE GEOGRAFIA E ESTATISTICA - IBGE. Estimativa da população brasileira. Rio de Janeiro, 2017. Disponível em: $\mathrm{ftp}$ //ftp.ibge.gov.br/Estimativas_de_Populacao/Estimativas_2017/.Acesso em: 18 fev. 2018.

INSTITUTO JONES DOS SANTOS NEVES. Pesquisa sobre população em situação de rua da Região Metropolitana da Grande Vitória: relatório. Vitória, 2018.

JOSSO, M.-C. Experiências de vida e formação. 2. ed. São Paulo: Paulus, 2004.

NATALINO, M. A. C. Estimativa da população em situação de rua no Brasil. Texto para discussão 2246. Brasília, DF: Instituto de Pesquisa Econômica Aplicada - Ipea, 2016. Disponível em: http://repositorio.ipea.gov.br/ bitstream/11058/7289/1/td_2246.pdf. Acesso em: 15 out. 2018. 
OLIVEIRA, W. F. Educação social de rua: bases históricas, políticas e pedagógicas. História, Ciências, Saúde-Manguinhos, Rio de Janeiro, v. 14, n. 1, p. 135-158, jan./mar. 2007. https://doi.org/10.1590/S0104-59702007000100007

SERRA (ES). Lei $n^{\circ} 2.678$, de 3 de março de 2004. Dispõe sobre a política de atendimento à população adulta de rua no município de Serra. Serra, 2004. Disponível em: http://legis.serra.es.gov.br/normas/images/leis/html/L26782004.html. Acesso em: 8 dez. 2017.

SOUZA NETO, J. C. Pedagogia social: a formação do educador social e seu campo de atuação. Vitória: UFES, 2010.

TRIVIÑOS, A. N. S. Introdução à pesquisa em ciências sociais: a pesquisa qualitativa em educação. São Paulo: Atlas, 1987.

VANGRELINO, A. C. S. O processo de formação de educadores sociais na área da infância e juventude. In: REUNIÃO DA ASSOCIAÇÃO NACIONAL DE PÓS-GRADUAÇÃO E PESQUISA EM EDUCAÇÃO, 28., Caxambu, 2005. Anais[...] Rio de Janeiro: Anped, 2005. Disponível em: http:/www.anped.org.br/sites/default/files/gt06430int.pdf.

Acesso em: 27 out. 2017.

VITÓRIA (ES). Lei Orgânica n 7.101, de 2 de outubro de 2007. Dispõe sobre a política de atendimento à população em situação de rua na cidade de Vitória e dá outras providências. Vitória, 2007. Disponível em: http://sistemas.vitoria. es.gov.br/webleis/Arquivos/2007/L7101.PDF. Acesso em: 30 nov. 2017.

ZUCCHETTI, D. T.; MOURA, E. P. G. Práticas socioeducativas e formação de educadores: novos desafios no campo social. Ensaio: Avaliação e Políticas Públicas em Educação, Rio de Janeiro, v. 18, n. 66, p. 9-28, jan./mar. 2010. https://doi.org/10.1590/S0104-40362010000100002 


\section{Informações dos autores}

Samuel Coelho da Silva: Professor da Educação Básica. Contato: samuel.ef@bol.com.br iD http://orcid.org/0000-0001-7171-7349

Rosianny Campos Berto: Doutora em Educação. Professora do Programa de Pós-Graduação em Educação da Universidade Federal do Espírito Santo. Contato: rosiannyb@gmail.com iD http://orcid.org/0000-0003-3143-3258

Liana Abrão Romera: Doutora em Educação Física. Professora do Programa de Pós-Graduação em Educação Física da Universidade Federal do Espírito Santo. Contato: liromera@uol.com.br

iD http://orcid.org/0000-0003-4809-2744 